\title{
SARS-CoV-2 IgG seroprevalence in blood donors located in three different federal states, Germany, March to June 2020
}

Bastian Fischer ${ }^{1}$, Cornelius Knabbe ${ }^{1}$, Tanja Vollmer ${ }^{1}$

1. Herz- und Diabeteszentrum NRW, Institut für Laboratoriums- und Transfusionsmedizin, Bad Oeynhausen, Germany

Correspondence: Bastian Fischer (bfischer@hdz-nrw.de)

Most cases of coronavirus disease 2019 are mild or asymptomatic. Therefore, many cases remain unrecorded. We determined seroprevalence of IgG antibodies against severe acute respiratory syndrome coronavirus 2 (SARS-CoV-2) in 3,186 regular blood donors in three German federal states between 9 March and 3 June 2020. The IgG seroprevalence was $0.91 \%$ (95\% confidence interval $(\mathrm{Cl}): 0.58-1.24)$ overall, ranging from $0.66 \%$ (95\% Cl: $0.13-1.19)$ in Hesse to $1.22 \%$ (95\% Cl: $0.33-2.10$ ) in Lower-Saxony.

Common symptoms of coronavirus disease 2019 (COVID-19) include cough, fever and respiratory problems. While ca $80 \%$ of infected people only show mild or no symptoms, some develop severe pneumonia, multiple organ failure or even die [1]. Current estimates assume a mortality rate of ca $2 \%$ in medically attended patients [2]. However, individuals with mild or no symptoms are not all included in these mortality estimates, and the number of unrecorded cases is unknown [3,4]. Although an acute infection with severe acute respiratory syndrome coronavirus 2 (SARS-CoV-2) is usually verified by $P C R$, a recent publication suggests a positive identification of anti-SARS-CoV-2 IgG antibodies as an acceptable approach to confirm infection [5].

To determine an approximation of the actual rate of people who have recovered from COVID-19, representative of the German population, we determined the anti-SARS-CoV-2 IgG seroprevalence of regular blood donors resident in three different German federal states between March and June 2020.

\section{Presence of anti-SARS-CoV-2 IgG in blood donors}

Residual material leftover from routine diagnostics from 3,186 regular blood donors without any preselection (2,257 (70.84\%) men and 929 (29.16\%) women), donated in the period between 9 March and 3 June 2020 , were screened for the presence of anti-SARS-CoV-2 IgG directed against domain $\mathrm{S}_{1}$ of the SARS-CoV-2 spike protein using the anti-SARS-CoV-2 enzyme-linked immunosorbent assay (ELISA) from Euroimmun (Lübeck, Germany). In recent publications, this serological ELISA showed a high specificity of $99-100 \%$ and a sensitivity of ca $65 \%$ [6-9]. Semiquantitative results were calculated as the ratio of the extinction of samples over the extinction of a calibrator. Seropositive results were confirmed using the Architect SARS-CoV-2 IgG (Abbott, Wiesbaden, Germany) targeting the viral nucleocapsid and the LIAISON SARS-CoV-2 S1/S2 IgG assay (DiaSorin Deutschland $\mathrm{GmbH}$, Dietzenbach, Germany) targeting the SARS-CoV-2 spike protein.

Most samples $(2,902 / 3,186 ;>91 \%)$ were obtained between 23 March and 22 May 2020. Samples were obtained from donors located in the three German federal states North Rhine-Westphalia $(n=1,700)$, Lower Saxony $(n=576)$ and Hesse $(n=910)$. Measurements were fully automated and processed according to the manufactures protocol using the Euroimmun Analyzer I system. Overall, we found an anti-SARS-CoV-2 IgG seroprevalence of $0.91 \%(29 / 3,186 ; 95 \% \mathrm{Cl}$ : 0.58-1.24) in our cohort; 24 male and five female donors. No statistical difference in seroprevalence was observed between men and women $(p=0.156)$. Likewise, the seroprevalence did not differ statistically between the three federal states $(p=0.536)$, but incidence was highest in Lower Saxony (1.22\%; 7/576; 95\% Cl: 0.33-2.10), followed by North Rhine-Westphalia (0.94\%; 16/1,700; 95\% Cl: 0.49-1.39) and Hesse (0.66\%; 6/910; 95\% Cl: o.13-1.19) (Table).

All donors underwent a medical examination before donation, reported that they did not have current or recent diseases and had no physically detectable symptoms of infection such as fever or an increased leukocyte count. None of the seropositive blood donors reported a known positive medical history of 
TABLE

Anti-SARS-CoV-2 IgG seroprevalence in regular blood donors, by region, Germany, March-June $2020(n=3,186)$

\begin{tabular}{|l|c|c|c|c|c|}
\hline \multirow{2}{*}{} & \multicolumn{3}{c|}{ IgG-positive } & \multicolumn{2}{c|}{ IgG-negative } \\
\cline { 2 - 6 } & $\mathrm{n}$ & $\%$ & $95 \% \mathrm{Cl}$ & $\mathrm{n}$ & $\%$ \\
\hline Overall & 29 & 0.91 & $0.58-1.24$ & 3,157 & 99.09 \\
\hline $\begin{array}{l}\text { North Rhine-Westphalia } \\
(\mathrm{n}=1,700)\end{array}$ & 16 & 0.94 & $0.49-1.39$ & 1,684 & 99.06 \\
\hline Lower Saxony $(\mathrm{n}=576)$ & 7 & 1.22 & $0.33-2.10$ & 569 & 98.78 \\
\hline Hesse $(\mathrm{n}=910)$ & 6 & 0.66 & $0.13-1.19$ & 904 & 99.34 \\
\hline
\end{tabular}

$\mathrm{Cl}$ : confidence interval; SARS-CoV-2: severe acute respiratory syndrome coronavirus 2 .

SARS-CoV-2 infection. A second retrospective survey for SARS-CoV-2 related symptoms was not conducted.

\section{Anti-SARS-CoV-2 IgG ratio distribution of seropositive blood donors}

The Figure shows the anti-SARS-CoV-2 IgG distribution in blood donors with equivocal (ratio: $\geq 0.8$ to $<1.1$ ) and clearly seropositive (ratio: $\geq 1.1$ ) test results. For clarity, values are presented in a histogram, choosing a binwidth of 0.2 (e.g. ratio $1.1-1.3$ ). The 29 seropositive donors showed a broad spectrum of IgG ratios ranging between 1.13 and 8.9. In addition, we identified nine blood donors with equivocal seropositive IgG antibody ratios ranking between 0.8 and 1.08 who were not considered for the seroprevalence calculation.

\section{Ethical statement}

We used exclusively waste material from routine laboratory diagnostics, therefore the need for informed consent and ethical approval was waived. Samples were collected in accordance with the German Act on Medical Devices for the collection of human residual material.

\section{Discussion}

After a public festival in February 2020, a local COVID19 outbreak occurred in Heinsberg, Germany. According to estimations by Streeck et al., this led to an infection rate of $15.5 \%$ (positive swab anamnesis and/or detection of anti-SARS-CoV-2 IgG antibodies), whereby $22.2 \%$ of infected individuals were asymptomatic [10]. The seroprevalence in non-hotspot regions is currently open to question. In our study, we decided to measure overall anti-SARS-CoV-2 IgG levels instead of neutralising antibodies, as not all individuals who have recovered from COVID-19 seem to express detectable neutralising antibody levels [11]. This would potentially lead to a number of false-negative results. As false-positive measurements could account for a considerable number in populations with a low seroprevalence, initial seropositive measurements were verified with two additional assays (Supplementary Figure S1). Consequently, we revised one initially seropositive tested result. We determined an overall low IgG seroprevalence of $0.91 \%$ ( $95 \% \mathrm{Cl}: 0.58-1.24$ ) against SARSCoV-2 in three German federal states. A recent study of the university hospital Eppendorf revealed comparable values for Hamburg. Their data show that fewer than $1 \%$ of 914 tested regular blood donors expressed IgG antibodies against the virus [12]. In addition, a national multicentre study, including four University children's hospitals in Baden-Württemberg, revealed that $1.3 \%$ of 4,932 individuals (children and their parents) tested between 22 April and 15 May expressed anti-SARSCoV-2 IgG antibodies [13].

It should be emphasised that the preselection of blood donors as study cohort is accompanied by limitations regarding representation of the population: Blood donors are between 18 and 65 years-old, young healthy adults are usually overrepresented and other groups (e.g. children, HIV/HCV/HBV-infected patients, older people with underlying conditions, institutionalised people) are excluded or underrepresented. Nevertheless, according to official data, only ca $0.2 \%$ of German citizens have so far (17 June 2020) been infected with the SARS-CoV-2 [14]. Therefore, our findings suggest that there are a large number of unrecorded cases.

Compared with hotspot regions either in Germany [10] or elsewhere in Europe (e.g. Lombardy, Italy, with a seroprevalence of $23 \%$ [15] and Madrid, Spain, with a seroprevalence of $11.5 \%$ (95\% Cl: 9.9-13.3) [16]), the low seroprevalence for SARS-CoV-2 determined in our study could be explained by the imposition of preventive, non-pharmaceutical, interventions at an early stage of the epidemic. A study by Flaxman et al. indicates that these lockdowns contributed considerably to the containment of virus spreading and therefore may have saved many lives [17]. Their model calculation estimating the current SARS-CoV-2 seroprevalence for different European countries revealed the lowest prevalence for Germany (0.85\%) and Norway (0.46\%), while higher values were estimated for Belgium (8\%) and Spain (5.5\%). All these rates are far too low to reach herd immunity, which would require ca $60 \%$ of the population to express protective antibodies against the virus [18].

In addition to the unambiguously seropositive blood donors, $0.3 \%$ of the individuals in our cohort showed equivocal levels of antibody. These donors may have been very recently infected and would subsequently have reached higher IgG antibody levels against SARSCoV-2. However, this assumes that they had an asymptomatic SARS-CoV-2 infection since blood donors represent a selection of apparently healthy individuals lacking any physically detectable symptoms. A longitudinal study on the antibody profile of SARSCoV-1 patients in 2006 showed that infected persons did not produce detectable antibody titres within the first 7 days after the onset of symptoms; IgG expression increased considerably on day 15 and reached a peak on day 60 [19]. First data for SARS-CoV-2 suggest a very similar timing of IgG antibody formation [20]. In addition, scientists from the university hospital Zurich 


\section{FIGURE}

Distribution of anti-SARS-CoV-2 IgG ratios of blood donors with seropositive and equivocal test results, Germany, March-June 2020, $(\mathrm{n}=3,186)$

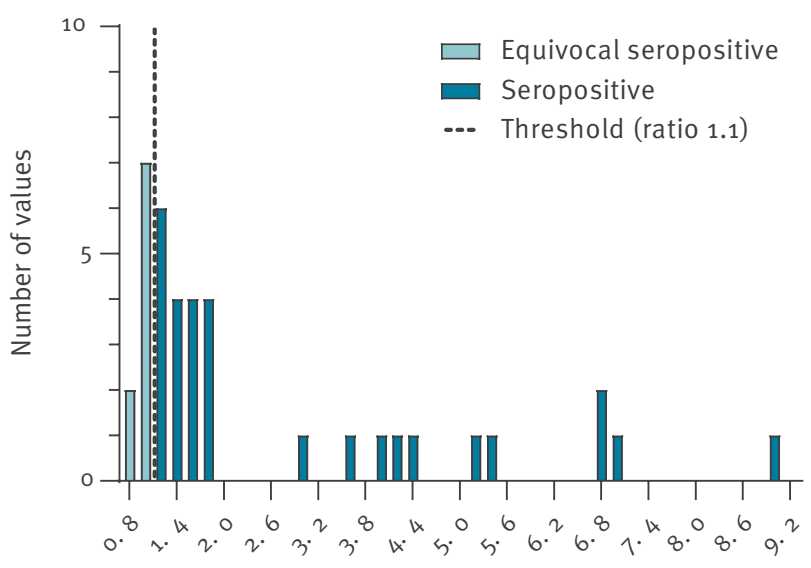

IgG ratio

SARS-CoV-2: severe acute respiratory syndrome coronavirus 2.

Equivocal were not considered for seroprevalence calculation. The dashed vertical line indicates the IgG seropositivity threshold (ratio $\geq 1.1$ ).

showed that serum IgG levels remained partially negative in COVID-19 patients with a mild disease progression, whereas severe cases, independently of age, had significantly increased serum IgG titres [21]. Long et al. monitored 285 recovered COVID-19 patients who tested positive for anti-SARS-CoV-2 IgG antibodies within 19 days after symptom onset but also here, seroconversion was delayed in patients with milder symptoms [22]. It is also conceivable, that individuals with a weak humoral immune response (low antibody ratio) have a stronger cellular immune response. In this context, $\mathrm{Wu}$ et al. recently presented a negative correlation between lymphocyte counts and neutralising antibody responses to SARS-CoV-2 in a cohort of COVID-19 recovered patients [11]. Interestingly, they also showed that 10 of 175 patients did not express detectable neutralising antibody titres at all.

\section{Conclusion}

Broad and comprehensive testing is required to better evaluate the number of people who have recovered from COVID-19 and to elucidate the magnitude of unrecorded cases. It has to be taken into consideration that not all convalescents seem to express detectable levels of anti-SARS-CoV-2 IgG antibodies and that there is missing evidence on antibody persistence.

\section{Acknowledgements}

We gratefully thank Birgit Drawe, Ricarda Plümers, Anika Kleine, Vanessa Schmidt, Janina Tiemann, Thanh-Diep Ly, Christopher Lindenkamp and Christoph Lichtenberg for their technical assistance.
Conflict of interest

None declared.

Authors' contributions

All authors have contributed significantly to the work and approved the final article. B. Fischer and T. Vollmer designed the study, analysed and interpreted the data and draft the manuscript. C. Knabbe designed the study and revised the manuscript critically.

\section{References}

1. Sharma R, Agarwal M, Gupta M, Somendra S, Saxena SK. Clinical characteristics and differential clinical diagnosis of novel coronavirus disease 2019 (COVID-19). In: Saxena S. (editor). Coronavirus disease 2019 (COVID-19). Medical virology: from pathogenesis to disease control. Springer, Singapore:2020; p 55-70. https://doi.org/ https://doi. org/10.1007/978-981-15-4814-7_6

2. Palacios Cruz M, Santos E, Velázquez Cervantes MA, León Juárez M. COVID-19, a worldwide public health emergency. Rev Clin Esp. 2020;So014-2565(20)30092-8. (Forthcoming). https://doi.org/10.1016/j.rceng.2020.03.001 PMID: 32204922

3. Day M. Covid-19: four fifths of cases are asymptomatic, China figures indicate. BMJ. 2020;369:m1375. https://doi. org/10.1136/bmj.m1375 PMID: 32241884

4. Day M. Covid-19: identifying and isolating asymptomatic people helped eliminate virus in Italian village. BMJ. 2020;368:m1165. https://doi.org/10.1136/bmj.m1165 PMID: 32205334

5. Zhang W, Du R-H, Li B, Zheng X-S, Yang X-L, Hu B, et al. Molecular and serological investigation of 2019-nCoV infected patients: implication of multiple shedding routes. Emerg Microbes Infect. 2020;9(1):386-9. https://doi.org/10.1080/222 21751.2020.1729071 PMID: 32065057

6. United States Food and Drug Administration (FDA). EUA authorized serology test performance. Silver Spring: FDA; 29 Jun 2020. Available from: https://www.fda.gov/ medical-devices/emergency-situations-medical-devices/ eua-authorized-serology-test-performance

7. Lassaunière R, Frische A, Harboe ZB, Nielsen ACY, Fomsgaard $A$, Krogfelt KA, et al. Evaluation of nine commercial SARSCoV-2 immunoassays. medRxiv. 2020.04.09.20056325 (preprint). https://doi.org/ https://doi.org/10.1101/2020.04.0 9.20056325

8. Montesinos I, Gruson D, Kabamba B, Dahma H, Van den Wijngaert S, Reza S, et al. Evaluation of two automated and three rapid lateral flow immunoassays for the detection of antiSARS-CoV-2 antibodies. J Clin Virol. 2020;128:104413. https:// doi.org/10.1016/j.jcv.2020.104413 PMID: 32403010

9. Meyer B, Torriani G, Yerly S, Mazza L, Calame A, ArmVernez I, et al. Validation of a commercially available SARS-CoV-2 serological immunoassay. Clin Microbiol Infect. 2020;S1198-743X(20)30368-2.

10. Streeck H, Schulte B, Kuemmerer B, Richter E, Hoeller T, Fuhrmann $C$, et al. Infection fatality rate of SARS-CoV-2 infection in a German community with a super-spreading event. medRxiv. 2020.05.04.20090076 (preprint). https://doi.org/ https://doi.org/10.1101/2020.05.04.20090076

11. Wu F, Wang A, Liu M, Wang Q, Chen J, Xia S, et al. Neutralizing antibody responses to SARS-CoV-2 in a COVID-19 recovered patient cohort and their implications. medRxiv 2020.03.30.20047365 (preprint).

12. Universitätsklinikum Eppendorf (UKE). Nur geringe Anzahl an Blutspendenden weist Antikörper gegen neuartiges CoronaVirus auf. [Only a small number of blood donations show antibodies against new coronavirus]. Hamburg: UKE; 9 Jun 2020. German. Available from: https://www.uke.de/allgemein/ presse/pressemitteilungen/detailseite_95424.html

13. Debatin K-M, Henneke P, Hoffmann GF, Kräusslich H-G, Renk $\mathrm{H}$. Prevalence of COVID-19 in children in Baden-Württemberg. Preliminary study report. Heidelberg: Universitätsklinikum Heidelberg. [Accessed date: 13 Jul 2020]. German. Available from: https://www.klinikum.uni-heidelberg.de/fileadmin/ pressestelle/Kinderstudie/Prevalence_of_COVID-19_in_ $\mathrm{BaWu}_{--} . \mathrm{pdf}$

14. Robert-Koch-Institut (RKI). COVID-19: Fallzahlen in Deutschland und weltweit. [COVID-19: Case numbers in Germany and worldwide]. Berlin: RKI. [Accessed: 17 Jun 2020]. German. 
Available from: https://www.rki.de/DE/Content/InfAZ/N/ Neuartiges_Coronavirus/Fallzahlen.html

15. Percivalle E, Cambiè G, Cassaniti I, Nepita EV, Maserati $R$, Ferrari A, et al. Prevalence of SARS-CoV-2 specific neutralising antibodies in blood donors from the Lodi Red Zone in Lombardy, Italy, as at 06 April 2020. Euro Surveill. 2020;25(24):2001031. https://doi.org/10.2807/1560-7917. ES.2020.25.24.2001031 PMID: 32583766

16. Pollán M, Pérez-Gómez B, Pastor-Barriuso R, Oteo J, Hernán MA, Pérez-Olmeda M, et al. Prevalence of SARS-CoV-2 in Spain (ENE-COVID): a nationwide, population-based seroepidemiological study. Lancet. 2020;S0140-6736(20)31483-5. (Forthcoming). PMID: 32645347

17. Flaxman S, Mishra S, Gandy A, Unwin HIT, Mellan TA, Coupland $\mathrm{H}$, et al. Estimating the effects of non-pharmaceutical interventions on COVID-19 in Europe. Nature. 2020. https:// doi.org/10.1038/s41586-020-2405-7 PMID: 32512579

18. Altmann DM, Douek DC, Boyton RJ. What policy makers need to know about COVID-19 protective immunity. Lancet. 2020;395(10236):1527-9. https://doi.org/10.1016/S01406736(20)30985-5 PMID: 32353328

19. Mo H, Zeng G, Ren X, Li H, Ke C, Tan Y, et al. Longitudinal profile of antibodies against SARS-coronavirus in SARS patients and their clinical significance. Respirology. 2006;11(1):49-53. https://doi.org/10.1111/j.14401843.2006.00783.x PMID: 16423201

20. Liu X, Wang J, Xu X, Liao G, Chen Y, Hu C-H. Patterns of IgG and IgM antibody response in COVID-19 patients. Emerg Microbes Infect. 2020;9(1):1269-74. https://doi.org/10.1080/22221751.2 020.1773324 PMID: 32515684

21. Cervia C, Nilsson J, Zurbuchen Y, Valaperti A, Schreiner J, Wolfensberger A, et al. Systemic and mucosal antibody secretion specific to SARS-CoV-2 during mild versus severe COVID-19. bioRxiv 2020.05.21.108308 (preprint). https://doi. org/ https://doi.org/10.1101/2020.05.21.108308

22. Long Q-X, Liu B-Z, Deng H-J, Wu GC, Deng K, Chen YK, et al. Antibody responses to SARS-CoV-2 in patients with COVID-19. Nat Med. 2020;26(6):845-8. https://doi.org/10.1038/s41591020-0897-1 PMID: 32350462

\section{License, supplementary material and copyright}

This is an open-access article distributed under the terms of the Creative Commons Attribution (CC BY 4.0) Licence. You may share and adapt the material, but must give appropriate credit to the source, provide a link to the licence and indicate if changes were made.

Any supplementary material referenced in the article can be found in the online version.

This article is copyright of the authors or their affiliated institutions, 2020. 